\title{
STRATEGI PENGEMBANGAN KEAMANAN PRODUK IKAN TUNA (Thunnus albacares) DAN MAHI-MAHI (Coryphaena hippurus) BEKU UNTUK EKSPOR KE BERBAGAI NEGARA DI KAWASAN INDUSTRI MAKASSAR (KIMA)
}

\section{Development Strategy Product Frozen Tuna Fish (Thunnus Albacares) and Mahi-Mahi (Coryphaena Hippurus) To Export To Various Countries Industrial areaIn Makassar (Kima)}

\author{
Ardiana 1), Andi Asni ${ }^{2)}$ dan Ernaningsih 2) \\ 1) PS Manajemen Pesisir dan Teknologi Kelautan PPS-UMI Makassar \\ 2) PS Pemanfaatan Sumberdaya Perikanan FPIK UMI Makassar \\ Korespondensi: ardianaamir@gmail.com \\ Diterima: tanggal 5 November 2018; Disetujui 29 November 2018
}

\begin{abstract}
Food safety is one of the requirements that become non-tariff barriers to enter the export market, mainly on the quality of products that do not meet quality standards set by the importing country. The purpose of this study is to analyze the causes and development of rejection of fishery products in the Makassar Industrial Area (KIMA) and the strategy of increasing the safety of frozen tuna and mahi-mahi products that are suitable for export to various export countries. The study was conducted on August 1 to September 302018 in the Makassar industrial area (KIMA). Using the Pareto diagram analysis method, causal analysis and SWOT Analysis. The results showed that during the years 2010-2017, six companies in the Makassar Industrial Area (KIMA) experienced cases of rejection caused by salmonella, filthy and histamine in 25 cases. The results of the priority analysis of fisheries product development strategies were based on the results of the analysis carried out. the best strategies in developing product development are as follows: (1) There is a need to provide comprehensive training on how to handle good catches for fishermen, suppliers by related agencies that are competent in their field; (2) Increased supervision of product quality processed by Quality Control (QC); (3) Companies must be able to review the causes of product rejection so that it does not recur from suppliers, every step of the process until delivery
\end{abstract}

Keywords: Product rejection, Filthy, Salmonella, Histamine, KIMA

\begin{abstract}
ABSTRAK
Keamanan pangan merupakan salah satu persyaratan yang menjadi hambatan non-tarif untuk memasuki pasar ekspor, utamanya pada kualitas produk yang tidak memenuhi standar kualitas yang ditetapkan negara pengimpor. Tujuan penelitian ini untuk menganalisis penyebab dan perkembangan penolakan produk perikanan di Kawasan Industri Makassar (KIMA) dan strategi peningkatan keamanan produk ikan tuna dan mahi-mahi beku yang tepat untuk ekspor ke berbagai negara ekspor. Penelitian dilaksanakan pada 01 Agustus sampai 30 September 2018 di Kawasan Industri Makassar (KIMA), metode yang digunakan adalah analisis diagram pareto, analisis sebab akibat, dan analisis SWOT. Hasil penelitian menunjukkan selama tahun 2010-2017, enam perusahaan di Kawasan Industri Makassar (KIMA) mengalami kasus penolakan yang disebabkan oleh salmonella, filthy dan histamine sebanyak 25 kasus. Strategi pengembangan produk perikanan berdasarkan hasil analisis yang dilakukan, ditetapkan 3 strategi terbaik dalam pengembangan produk adalah: (1) Perlu adanya pemberian pelatihan secara menyeluruh mengenai cara penanganan hasil tangkapan yang baik terhadap nelayan, supplier oleh dinas terkait yang berkompeten dibidangnya; (2) Peningkatan pengawasan terhadap kualitas produk yang diproses oleh Quality Control (QC); (3) Perusahaan harus mampu melakukan penelusuran terhadap penyebab penolakan produk agar tidak terulang kembali mulai dari supplier, setiap tahapan proses sampai pengiriman.
\end{abstract}

Kata Kunci: Penolakan produk, Salmonella, Filthy, Histamine, KIMA 


\section{PENDAHULUAN}

Pada era perdagangan bebas, produk perikanan Indonesia menghadapi berbagai tantangan untuk meningkatkan daya saing, baik dalam mutu produk maupun efisiensi dalam produksi. Tantangan terbesar bagi produk pangan termasuk produk perikanan di Indonesia yang paling utama adalah keamanan pangan.

Standar untuk keamanan pangan (food safety) yang dirumuskan oleh Codex Alimentarius Commission dan secara internasional telah diakui adalah sistem mutu Hazard Analysis Critical Control Points (HACCP). Sistem mutu HACCP merupakan sistem yang dikembangkan dengan prinsip dimana pengawasan mutu dilakukan secara sistematis, terpadu sejak dari awal sampai produk siap dikonsumsi. Sistem mutu HACCP merupakan syarat dasar yang harus dipenuhi oleh semua perusahaan perikanan yang akan melakukan ekspor produknya ke Amerika Serikat dan Uni Eropa yang diberlakukan sejak tahun 1995 berdasarkan ketentuan Code of Conduct Responsible Fisheries (CCRF).

Persyaratan kemanan pangan dari negara importir yang ditetapkan dalam bentuk peraturan sering menjadi penghambat dalam perdagangan. Standar, regulasi, badan pengawas mutu dan penerapan standar di lapangan yang berbeda antara negara importir dan eksportir menjadi alasan utama penolakan yang terjadi pada hampir seluruh negara eksportir (Ababouch, 2005). Selama tahun 2005- 2014 Indonesia mengalami kasus penolakan produk ikan oleh US-FDA sebanyak 699 kasus dan oleh Europa-RASFF sebanyak 29 kasus. Produk ikan yang paling banyak ditolak adalah ikan Tuna sejumlah 441 kasus (63\%) di Amerika Serikat dan 15 Kasus (51\%) di Uni Eropa. Masalah utama terjadinya kasus penolakan produk ikan asal Indonesia adalah filthy dan Salmonella di Amerika Serikat dan mercury, histamine dan poor temperature control di Uni Eropa. Kebijakan perdagangan terkait keamanan produk perikanan yang berpengaruh terhadap kinerja ekspor ikan Indonesia oleh Amerika Serikat adalah FDA Food Code dan Fishery Products Hazards and Controls Guidance dan pada Uni Eropa adalah Commission Decision. Harmonisasi regulasi terkait keamanan pangan dan perbaikan teknis serta pengawasan mutu hasil perikanan diperlukan untuk mengurangi penolakan produk ikan Indonesia di pasar ekspor. (Hartana, 2014).

\section{MATERI DAN METODE}

Penelitian ini dilaksanakan selama kurang lebih 2 (dua) bulan, yakni pada bulan 01 Agustus sampai 30 September 2018. Lokasi penelitian terletak di Kawasan Industri Makassar (KIMA). 


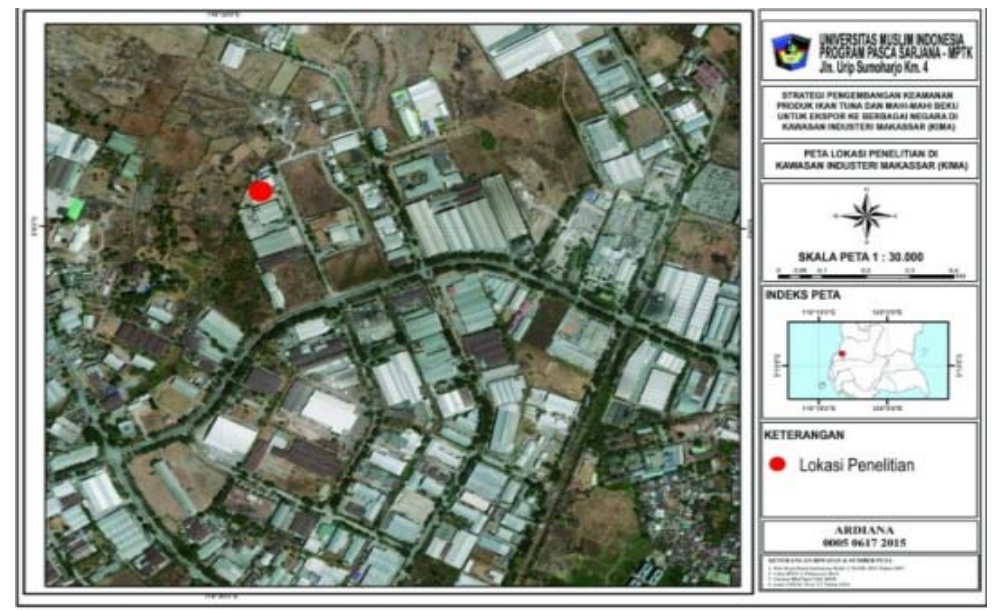

Gambar 1. Peta Lokasi Penelitian

Alat dan bahan yang digunakan dalam penelitian ini yaitu Komputer, alat tulis menulis, kuesioner, Website FDA, Website RASFF dan Website BKIPM. Penelitian ini menggunakan metode observasi dilakukan dengan cara mengakses Website FDA yang dipublikasikan oleh United State-Food and Drug Administration (US-FDA), website Europa-Rapid Alert System for Food and Feed (RASFF) dengan mengakses.

wawancara/interview

Teknik

sampling dari beberapa UPI di

Kawasan Industri Makassar (KIMA), Balai Besar KIPM Makassar, supplier dan nelayan untuk mendapatkan informasi dengan menggunakan kuesioner, dokumentasi yaitu mengumpulkan dokumen-dokumen dan foto-foto di lapangan yang mendukung penelitian.

Metode penentuan responden di Kawasan Industri Makassar (KIMA) dilakukan secara menyeluruh pada perusahaan yang memproduksi ikan Tuna dan mahi-mahi yang telah mengalami kasus penolakan. Data mengenai penolakan perikanan dalam penelitian ini bersumber dari responden dan informan yang dianggap terlibat langsung dan berkompeten dibidang perikanan. Hal tersebut bertujuan agar semua lapisan dapat terwakili (Nelayan, supplier, UPI, dan aparatur pemerintah).

Analisis data dilakukan dalam 3 (tiga) tahap berurutan, yaitu : i) analisis penyebab dan perkembangan produk yang ditolak, ii) strategi pengembangan keamanan produk perikanan untuk ekspor dilakukan dengan metode SWOT. Masing-masing analisis tersebut dijelaskan pada bagian berikut ini.

Diagram pareto merupakan suatu gambar yang mengurutkan klasifikasi data dari kiri ke kanan menurut urutan rangking tertinggi hingga terendah, sehinga ditemukan permasalahan yang penting untuk segera diselesaikan (dari rangking tertinggi hingga terendah) (Atmaja, 2005).

Rumus diagram Pareto:

$$
\text { Persentase }=\frac{\text { Jumlah perjenis }}{\text { Jumlah Keseluruhan| }} \quad \times 100 \%
$$


Keterangan :

Jumlah Perjenis jenis penyebab

Jumlah Keseluruhan

keseluruhan penyebab

Langkah-langkah membuat diagram pareto :

- Menentukan metode atau arti dari pengklasifikasian data, misalnya berdasarkan masalah, penyebab, jenis ketidaksesuaian dan sebagainya

- Menentukan satuan yang digunakan untuk membuat urutan karakteristikkarakteristik tersebut, misalnya frekuensi, unit dan sebagainya

- Mengumpulkan data sesuai dengan interval waktu yang telah ditentukan

- Merangkum data dan membuat rangking kategori data tersebut dari yang terbesar dan terkecil

- Menghitung frekuensi kumulatif atau persentase kumulatif yang digunakan

- Menggambar diagram batam, menunjukkan tingkat kepentingan relatif masing-masing masalah.

Diagram sebab akibat menggambarkan garis dan simbolsimbol yang menunjukkan hubungan antara akibat dan suatu masalah. Diagram tersebut memang digunakan untuk mengetahui akibat dari suatu masalah untuk selanjutnya diambil tindakan perbaikan. Secara umum terdapat lima faktor yang berpengaruh seperti : Lingkungan, manusia, metode, bahan, mesin peralatan, manajemen. Diagram sebab akibat hanya merupakan alat untuk mengidentifikasi faktor-faktor yang berpeluang menjadi penyebab masalah, bukan mangidentifikasi masalah (Muhandri, 2008).

Analisis yang digunakan untuk menentukan strategi pengembangan keamanan produk perikanan untuk ekspor ke berbagai negara di Kawasan Industri Makassar adalah analisis SWOT. Menurut Rangkuti (2009), analisis SWOT adalah analisis yang berguna untuk memperoleh formulasi strategi yang tepat, dan disesuaikan dengan kondisi dan potensi wilayah. Analisis SWOT digunakan untuk mengidentifikasi dan mengevaluasi faktor internal dan eksternal, yang didasarkan pada logika untuk memaksimalkan kekuatan (Strengths) dan peluang (Opportunities), namun secara bersamaan dapat meminimalkan kelemahan (Weaknesses) dan ancaman (Threats). Pembobotan dalam SWOT dilakukan dengan perhitungan terhadap point faktor yang dilaksanakan secara saling ketergantungan. Artinya, penilaian terhadap satu point faktor adalah dengan membandingkan tingkat kepentingannya dengan faktor lainnya, sehingga perhitungannya adalah nilai yang didapat (rentang nilainya sama dengan banyaknya point faktor dibagi dengan banyaknya jumlah point faktor) (BPS, 2009).

\section{HASIL DAN PEMBAHASAN}

\section{Gambaran Umum Lokasi Penelitian}

PT. KIMA sebagai Kawasan Industri Pemerintah merupakan wahana untuk lokasi industri yang berwawasan lingkungan yang dalam kurung waktu ini mengalami perkembangan pesat dan mendapat 
pengakuan Internasional berupa Perusahaan tersebut telah melakukan sertifikat ISO 9001, menjadi ekspor ke beberapa Negara tujuan perusahaan BUMN terbaik serta diantaranya: Eropa, Amerika, Asia dan peringkat pertama Kawasan Industri Australia. Adapun jenis olahan UPI dalam Lingkungan Kementerian yang ada dilihat pada (Gambar 2). BUMN (PT. KIMA, 2018). PT. KIMA merupakan pusat perindustrian terutama industri yang bergerak dibidang perikanan, terdapat sebanyak 74 perusahaan dari 114 UPI yang ada di Sulawesi Selatan yang mengolah berbagai macam hasil perikanan seperti jenis ikan, crustacea, molusca, rumput laut, dan lain-lain (BKIPM, 2018).

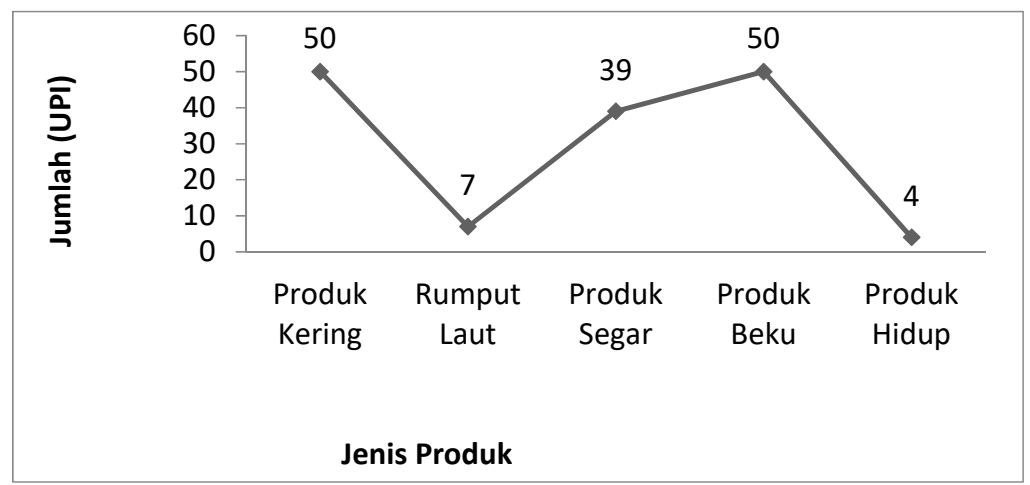

Gambar 2. Jumlah UPI Menurut Jenis olahan yang ada di KIMA

Jenis produk yang diolah rendah yaitu produk rumput laut perusahaan bermacam-macam, jenis sebanyak 7 UPI dan produk hidup olahan yang paling banyak yaitu sebanyak 4 UPI, jenis produk yang produk kering dan dan produk beku diolah oleh perusahaan dapat dilihat yaitu masing-masing 50 UPI, pada (Gambar 3) sedangkan olahan produk yang paling

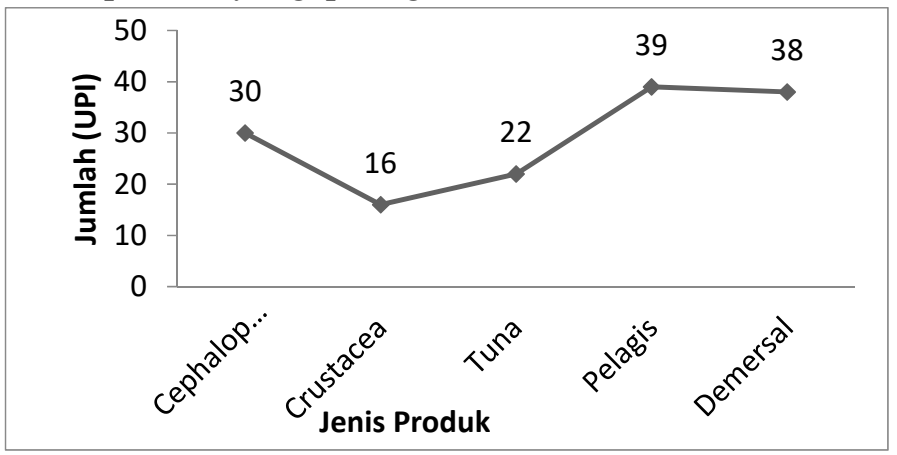

Gambar 3. Jumlah UPI Menurut Komoditas yang ada di KIMA 
Perkembangan Penolakan Produk Perikanan Indonesia Oleh FDA

Selama tahun 2010-2017, Indonesia mengalami kasus penolakan di Amerika Serikat sebanyak 3,296 kasus penolakan produk pangan. Setiap tahunnya terjadi lebih dari 240 kasus penolakan produk pangan Indonesia di Amerika Serikat oleh US-FDA dengan rata-rata tiap tahun terjadi 412 kasus penolakan. Jumlah kasus penolakan produk pangan tiap tahunnya selama tahun 2010-2017 tersaji pada (Gambar 4)

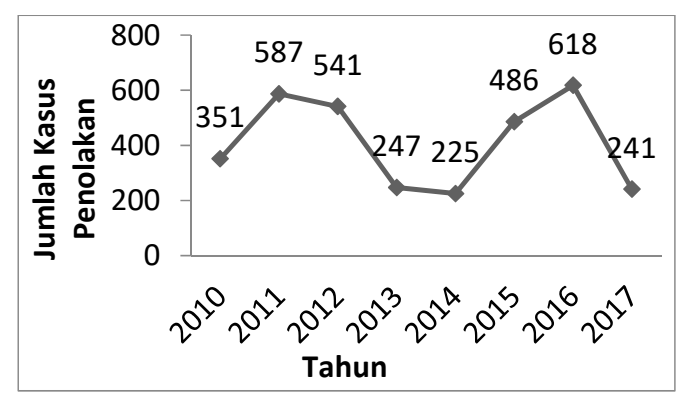

Gambar 4. Perkembangan Jumlah Kasus Penolakan Produk Pangan Indonesia di Amerika Serikat selama Tahun 2010-2017 (FDA, 2018).

Kasus penolakan produk 2017 di KIMA disebabkan oleh perikanan juga terdapat di Kawasan beberapa hal dapat dilihat pada (Tabel Industri Makassar (KIMA) tahun 2010- 3).

Tabel 3. Jenis Produk dan Penyebab Penolakan Produk Perikanan di KIMA

\begin{tabular}{lll}
\hline \multicolumn{1}{c}{ Nama Perusahaan } & Jenis Produk Yang Ditolak & Penyebab Penolakan \\
\hline PT. Prima Bahari & Tuna Beku & Salmonella \\
PT. Chen whoo Fishery & Tuna Beku & Filthy \& Salmonella \\
PT. Usaha Centraljaya Sakti & Tuna Beku & Salmonella \\
PT. Nusa Cipta Magello & Tuna Beku & Salmonella \\
PT. Kemilau Bintang Timur & Tuna \& Mahi-mahi Beku & Filthy \\
PT. Sukses Hasil Alam Nusaindo & Mahi-mahi Beku & Filthy, Histamine \& \\
& & Salmonella \\
\hline
\end{tabular}

Berdasarkan Tabel 3 produk yang paling banyak mengalami penolakan yaitu Tuna beku dengan alasan penolakan yang terjadi pada produk perikanan ekspor dari KIMA terbanyak adalah karena alasan Salmonella, filthy dan histamine. Hal ini terjadi karena pada beberapa produk mengalami penolakan lebih dari dua alasan. Alasan Salmonella merupakan alasan yang paling banyak terjadi di
KIMA. Alasan Salmonella terjadi jika pada produk pangan tersebut mengandung Salmonella, zat beracun dan merusak yang dapat membahayakan kesehatan (FDA, 2011). Salmonella merupakan salah satu bakteri patogen yang berperan penting sebagai indikator keamanan dan berpengaruh sangat besar pada kesehatan manusia. Bakteri ini merupakan salah satu bakteri yang 
paling umum menyebabkan penyakit keracunan pangan di negara sedang berkembang dan negara berkembang (Del-Portillo 2000 dalam Rahmawaty, 2013). Salmonella dalam pangan perlu mendapat perhatian karena umumnya terdapat dalam jumlah kecil tetapi jumlah tersebut cukup untuk menimbulkan gejala penyakit (Jenie dan Fardiaz 1989). Standar salmonella yang ditetapkan oleh buyer maupun Standar Nasional Indonesia (SNI) yaitu Negatif, sedangkan pada kasus penolakan ditemukan hasil uji Salmonella Positif sehingga mengalami penolakan dan produk dikembalikan ke perusahaan yang bersangkutan. Kasus dengan alasan filthy ini terjadi jika dalam produk pangan tersebut mengandung sesuatu yang tidak selayaknya ada dalam bahan pangan tersebut seperti berbau dan warna tidak cerah. Standar filthy pada produk yang di ekspor harus nol (0)/ tidak ada, sedangkan beberapa produk yang diekpor setelah dilakukan pengambilan sample ditemukan filthy pada sample produk ikan tuna dan mahi-mahi, sehingga dengan temuan ini produk dikembalikan ke perusahaan yang bersangkutan. Alasan histamine terjadi jika pada produk pangan tersebut mengandung histamine atau zat beracun yang merusak dengan jumlah yang dapat membahayakan kesehatan (FDA, 2011). Keberadaan histamine dalam jumlah yang besar pada ikan yang mengalami pembusukan dapat menyebabkan keracunan atau kematian, khususnya untuk ikan-ikan golongan Scombroidae (Taylor 1983 dalam Saputra, 2011). Histamine terjadi sebanyak 1 kasus dari 25 kasus, standar histamine yang ditetapkan oleh buyer dan SNI yaitu $<50$ ppm, sedangkan di sample produk mahimahi PT. Sukses Hasil Alam Nusaindo ditemukan kadar histamine $>50 \mathrm{ppm}$, sehingga produk mahi-mahi dikembalikan ke perusahaan.

Kasus penolakan akibat dari bakteri salmonella sangat banyak terjadi pada produk ikan tuna, sehingga perlu ditekankan ikan tuna harus ditangani dengan baik, mulai dari aktivitas penangkapan, proses, hingga pengapalan. Apabila tidak ditangani dengan baik, produk tuna Indonesia sulit untuk mendapat pasar ekspor yang menerapkan standar kualitas dan mutu yang tinggi. Praktik penangkapan yang berkelanjutan itu denganhandline, tetapi masih banyak nelayan yang menggunakan perahu kecil tidak mengangkut ikan secara gelondongan. Saat proses pemotongan, bakteri bisa masuk, ke dalam daging ikan dari kontaminasi dari air, nelayan dan peralatan yang digunakan.

\section{Diagram pareto}

Diagram Pareto merupakan diagram yang terdiri atas grafik balok dan grafik garis yang menggambarkan perbandingan masing-masing jenis data terhadap keseluruhan. Dengan memakai Diagram Pareto, dapat terlihat masalah mana yang sedikit tapi dominan (vital view) dan masalah yang banyak tetapi kurang dominan (trivial many) (Muhandri dan Kadarisman 2008). Untuk mengetahui penyebab masalah terjadinya kasus penolakan pada produk perikanan dengan 
menggunakan diagram Pareto. untuk masalah utama pada kasus yang Gambar 5 menunjukan diagram Pareto terjadi di Amerika Serikat.

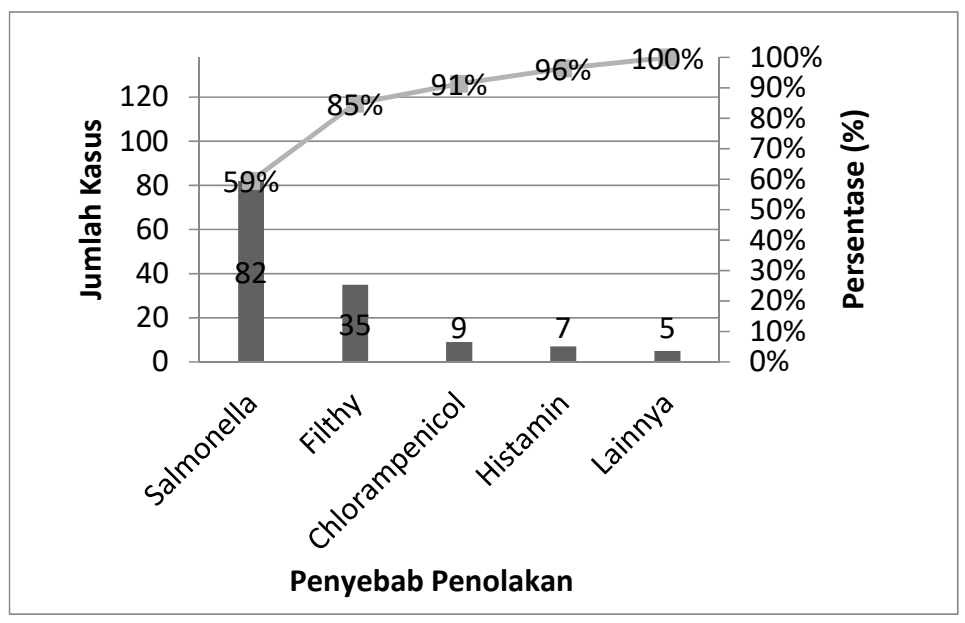

Gambar 5. Diagram Pareto untuk Masalah Utama Kasus Penolakan Produk Ikan Tuna di Amerika Serikat selama tahun 2010-2017

Dalam diagram pareto diatas tingginya kasus bakteri salmonella dapat dilihat bahwa Salmonella pada produk ikan (seafood) (Aziz 2009 merupakan merupakan vital view dalam Saputra, 2011). Habitat utama (masalah utama) terjadinya kasus salmonella adalah saluran usus hewan penolakan produk ikan tuna di (burung, reptile, hama tanaman) dan Amerika Serikat selama tahun 2010- manusia. Salmonella juga terdapat di 2017. Penyebab terjadinya alasan bagian tubuh yang lain serta di udara salmonella pada produk pangan adalah terutama udara yang tercemar (Jay et adanya sumber-sumber kontaminasi al., 2005). Wadah penyimpanan yang yang menyebabkan produk pangan tidak tertutup dan lamanya waktu terkontaminasi bakteri salmonella. pendistribusian ke luar negeri dapat Sumber-sumber kontaminasi meliputi meningkatkan kontaminasi salmonella faktor lingkungan seperti tempat pada produk pangan. Selain itu, proses penangkapan, pengolahan, dan pemasakan atau pemanasan terhadap pendistribusian yang kurang bersih produk pangan yang kurang dapat sehingga pangan mudah terkontaminasi membuat salmonella masih oleh mikroba dari udara dan sekitarnya. mengontaminasi produk pangan Selain itu terdapat faktor lain termasuk tersebut. Aplikasi suhu tinggi pada kurangnya suplai air bersih, pemasakan ataupun proses pasteurisasi ketidakcukupan proes sanitasi, pangan adalah cara terbaik untuk buruknya higienitas, dan masalah membunuh salmonella, ketahanan keamanan pangan yang menyebabkan salmonella dalam air sangat tinggi. 
Bahkan bakteri ini dapat bertahan saat terjadi peningkatan salinitas yang terjadi secara cepat dan stress tekanan osmotic yang berkepanjangan dengan cara bergabung dengan cairan limbah dalam air payau (Shabarinath et al. 2007 dalam Saputra, 2011). Dalam kasus yang terjadi oleh RASFF, alasan penolakan cukup berbeda dengan alasan yang terjadi oleh US-FDA. Gambar 6 menunjukkan diagram pareto untuk masalah utama pada kasus yang terjadi di Eropa oleh EuropaRASFF.

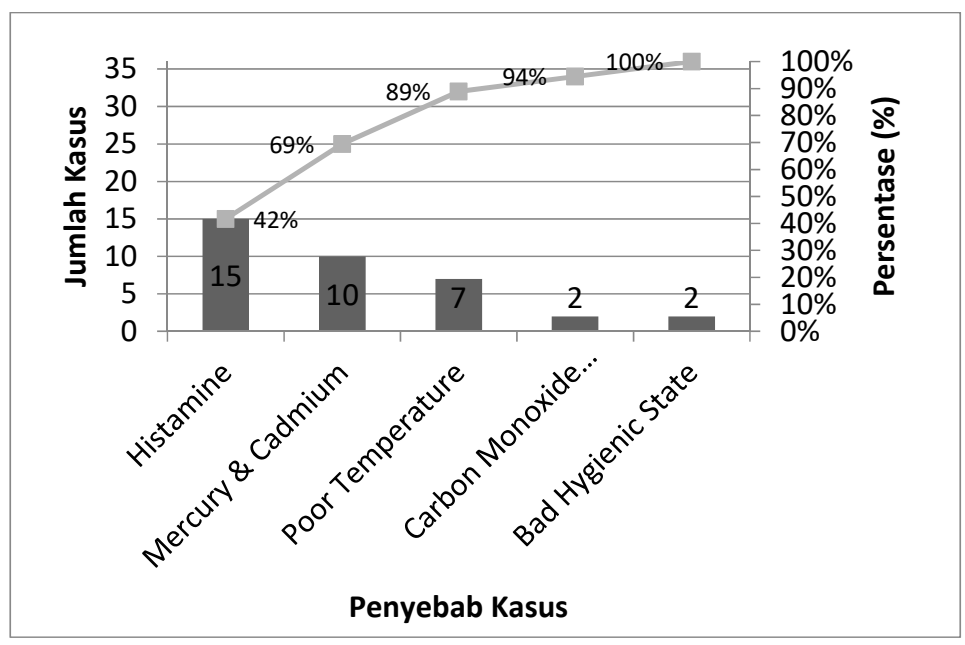

Gambar 5. Diagram Pareto untuk masalah utama kasus penolakan produk ikan tuna yang terjadi di Eropa oleh Europa-RASFF selama tahun 20102017

Pada Gambar 6 terlihat bahwa alasan penyebab penolakan histamine merupakan vital view (masalah utama) pada kasus penolakan produk perikanan yang terjadi di Eropa oleh Europa RASFF selama tahun 2010-2017. Histamine terdapat pada ikan tuna karena yang termasuk ikan laut dalam spesies Scombridae, bermarga Thunnus, berdaging merah muda sampai merah tua karena otot ikan tuna mengandung lebih banyak mioglobin dari pada ikan lainnya. Spesies Scombridae menyebabkan sindrom scromboid yang dihasilkan dari penanganan yang tidak sesuai selama pengolahan atau penyimpanan. Salah satu komponen beracun penyebab keracunan Scombroid adalah histidin, yang dipecah menjadi histamine. Ikan tuna secara alami mengandung histidin. Pada suhu di atas $16^{\circ} \mathrm{C}\left(60^{\circ} \mathrm{F}\right)$ dan jika terjadi kontak udara maka histidin dikonversi ke histamine oleh enzim histidin dekarboksilase yang diproduksi oleh bakteri enterik termasuk Morganella morganii (ini adalah salah satu alasan mengapa ikan harus disimpan pada suhu rendah). Histamine tidak hancur oleh suhu memasak normal. Histamine adalah mediator reaksi alergi, sehingga dapat menghasilkan gejala respon alergi yang parah (Kim et al. 1999). Pencegahan dekomposisi histidin menjadi histamine dapat dilakukan dengan pengaturan suhu dan waktu, yaitu pada suhu $<4.4^{\circ} \mathrm{C}$ 
dalam waktu 8 jam, apabila suhu pengolahan berfluktuasi maka waktu pengolahan harus diperketat kurang dari 4 jam (Kerr et al. 2002).

\section{Analisis Sebab Akibat}

Penolakan produk perikanan Berdasarkan diagram sebab akibat diatas terdapat tiga faktor yang berpengaruh yaitu manusia, peralatan dan metode:

\section{1) Manusia}

Manusia dalam hal ini yaitu nelayan dan karyawan yang bekerja pada industri pengolahan ikan. Faktor manusia sangat mempengaruhi mutu akhir produk yang dihasilkan. Alasan penolakan yang terjadi di Amerika Serikat dan Eropa lebih banyak dikarenakan produk mengandung bakteri salmonella, filthy dan histamine. Penolakan dengan alasan salmonella sangat berpengaruh dengan faktor manusia. Alasan salmonella dan histamine terjadi karena penanganan dan pengolahan yang tidak baik, sehingga manusia, dalam hal ini nelayan dan karyawan yang tidak tahu cara penanganan dan pengolahan yang baik maka akan mempengaruhi mutu produk. Keahlian dalam hal penanganan dan pengolahan produk harus dimiliki oleh setiap karyawan atau nelayan sehingga tahu apa saja yang harus dan tidak dilakukan agar mutu produk tetap baik.

\section{2) Peralatan}

Peralatan yang digunakan selama proses penanganan diatas kapal dan di pabrik pengolahan sangat berpengaruh besar terhadap timbulnya bakteri salmonella, jika nelayan menggunakan peralatan yang tidak bersih untuk penanganan ikan tuna diatas kapal maka bakteri bisa muncul akibat dari peralatan yang tidak bersih tersebut, begitupun peralatan yang digunakan di pabrik pengolahan seperti pisau, basket, meja dan fish box yang digunakan harus bersih.

3) Metode

Metode dalam penaganan ikan tuna harus sesuai dengan standar yang dimulai dari penanganan ikan yang baik sejak ditangkap sampai pengolahan. Beberapa cara untuk menjaga mutu ikan agar bebas dari bahaya bakteri salmonella dan histamine adalah dengan menurunkan suhu penanganan dan penyimpanan, pencucian yang efektif untuk mengurangi kemungkinan terkontaminasi, mencegah penyinaran langsung dari sinar matahari, dan mencegah kontak langsung dengan udara bebas (Astawan, 2001).

\section{Arahan Strategi Pengembangan Produk Ikan Tuna dan Mahi-mahi Beku}

Prioritas strategi pengembangan produk perikanan ikan tuna dan mahimahi beku berdasarkan hasil analisis yang dilakukan, ditetapkan 9 strategi terbaik pengembangan produk perikanan di Kawasan Industri Makassar (KIMA) antara lain sebagai berikut:

1. Meningkatkan kualitas produk agar selalu memenuhi standard

2. Memberikan pelatihan HACCP (GMP dan SSOP) terhadap QC dan karyawan secara berkala

3. Menerima bahan baku dari supplier yang sudah memiliki sertifikat CPIB 
4. Memperbaiki sistem manajemen perusahaan

5. Meningkatkan kualitas potensi SDM (Karyawan) agar mampu menghasilkan produk yang berkualitas

6. Memperluas cakupan distribusi produk ikan beku

7. Menambah dan menjaling hubungan kerja sama antara supplier

8. Bekerjasama dengan pemerintah untuk meningkatkan hubungan dengan perdagangan luar negeri

9. Meningkatkan promosi produk perusahaan.

\section{KESIMPULAN}

Berdasarkan hasil penelitian yang telah dilakukan di Kawasan Industri Makassar (KIMA) dapat ditarik kesimpulan sebagai berikut:

1. Selama tahun 2010-2017, enam perusahaan di Kawasan Industri Makassar (KIMA) mengalami kasus penolakan yang disebabkan oleh salmonella, filthy dan histamine sebanyak 25 kasus .

2. Prioritas strategi pengembangan produk perikanan berdasarkan hasil analisis yang dilakukan, ditetapkan 3 strategi terbaik dalam pengembangan pengembangan produk adalah sebagai berikut: (1) Perlu adanya pemberian pelatihan secara menyeluruh mengenai cara penanganan hasil tangkapan yang baik terhadap nelayan, supplier oleh dinas terkait yang berkompeten dibidangnya; (2)
Peningkatan pengawasan terhadap kualitas produk yang diproses oleh Quality Control (QC); (3) Perusahaan harus mampu melakukan penelesuran terhadap penyebab penolakan produk agar tidak terulang kembali mulai dari supplier, setiap tahapan proses sampai pengiriman

\section{SARAN}

1. Perlu dilakukan penelitian lanjutan terhadap pengembangan produk ikan tuna dan mahi-mahi beku.

2. Untuk otoritas kompeten di bidang perikanan ekspor harus lebih sering melakukan audit, pelatihan dan pengawasan terhadap produk perikanan mulai dari hulu (nelayan) sampai hilir (perusahaan).

\section{UCAPAN TERIMA KASIH}

Penulis mengucapkan terima kasih kepada pihak manajemen PT. Kawasan Industri Makassar (KIMA) yang telah memberikan dukungan berupa izin dalam pengumpulan data-data penelitan, demikian juga perusahaan-perusahaan lokasi penelitian hingga selesai serta para pembimbing dan para reviewer yang telah banyak memberikan masukan dan komentar untuk memperbaiki tulisan ini.

\section{DAFTAR PUSTAKA}

Astawan M. 2001. Penanganan dan Pengolahan Hasil Perikanan. Jakarta : Universitas Terbuka.

BKIPM, Balai Karantina Ikan, Pengendalian Mutu dan hasil 
Perikanan, 2018. BKIPM Statistik, volume Ekspor, Balai Besar KIPM Makassar.

Hartana R, 2014, Analisis Penolakan Produk Ikan Indonesia di pasar Eropa dan Amerika Serikat. Jurusan Perikanan, Fakultas Pertanian Universitas Gadjah Mada, Yogyakarta

Kerr M, Lawicki P, Aguirre S dan Rayner C. 2002. Effect of Storage Conditions on Histamine Formation in Fresh and Canned Tuna. Victoria: Public Health Division Victorian Government Department of Human Services.

Muhandri. T, Kadarisman D. 2008. Sistem Jaminan Mutu Industri Pangan. Edisi 2. Bogor : IPB Press
Rahayu., W. 2013. Pengembangan Strategi Keamanan Produk Perikanan Untuk Ekspor $\mathrm{Ke}$ Amerika Serikat, Institut Pertanian Bogor, Kampus IPB Darmaga

Saputra M, 2011 Analisis Alasan Penolakan Produk Pangan Ekspor Indonesia Oleh Amerika Serikat dan Eropa Selama Tahun 2002-2010 Fakultas Teknologi Pertanian Institut Pertanian Bogor Serikat [skripsi]. Palembang: Fakultas Pertanian, Universitas Sriwijaya. 